\title{
Mapeamento de públicos para iniciativas acadêmicas de arquivamento da web
}

Mapping of audiences for academic web archiving initiatives

Mapeo de públicos para iniciativas acadêmicas de archivamiento web

DOI: https://doi.org/10.1590/1809-5844202014

\section{Marina Rodrigues Martins ${ }^{1}$}

https://orcid.org/0000-0002-6815-815X

\section{Moisés Rockembach ${ }^{1}$}

https://orcid.org/0000-0001-9057-0602

${ }^{1}$ (Universidade Federal do Rio Grande do Sul, Faculdade de Biblioteconomia e Comunicação, Programa de Pós-Graduação em Comunicação. Porto Alegre - RS, Brasil).

\section{Resumo}

O estudo apresenta a potencial rede de públicos estratégicos da Universidade Federal do Rio Grande do Sul, visando promover iniciativas de arquivamento da web no âmbito acadêmico. Levou em conta o ambiente relacional projetado a partir dos Órgãos da Administração Superior e do Programa de Pós-Graduação em Comunicação, da Faculdade de Biblioteconomia e Comunicação da Universidade. Como referência, se observou as iniciativas implantadas e as estruturas organizacionais da Universidade de Columbia e da Universidade de Harvard. A metodologia englobou pesquisas bibliográfica, documental e de conteúdo. O entendimento sobre públicos ocorreu a partir dos enfoques da conceituação lógica, do poder e da comunicação. O estudo concluiu que os atores organizacionais exercem influência em diferentes níveis, cada um conforme suas responsabilidades. Quanto maior a quantidade de coleções arquivadas, mais complexas as redes de públicos envolvidos, de seus diferentes sujeitos dependem apoio financeiro, de infraestrutura, tecnológico, jurídico etc.

Palavras-chave: Arquivamento da web. Arquivo web. Mapeamento de públicos. Relações Públicas. Perfil de públicos.

\begin{abstract}
This study presents the potential network of strategic audiences of the Federal University of Rio Grande do Sul, aiming to promote web archiving initiatives in the academic field. It considered the relational environment projected from the Higher Administrative Bodies and the Graduate Program in Communication of the Faculty of Library Science and Communication of this University. As a reference, we have observed the initiatives implemented and the organizational
\end{abstract}


structures of Columbia University and Harvard University. The methodology encompassed bibliographical, documentary and content research. The understanding about audiences came from the approaches of logical conceptualization, power and communication. The study concluded that organizational actors influence at different levels within institutional structures, each according to their responsibilities. The larger the number of archived collections, the greater the network of audiences involved, of their different subjects depend financial, infrastructure, technological, legal and other support.

Keywords: Web archiving. Web archive. Mapping audiences. Public Relations. Public profile.

\section{Resumen}

Este estudio presenta la potencial red de audiencias estratégicas de la Universidade Federal de Rio Grande do Sul, con el objetivo de promover iniciativas de archivo de la web en el campo académico. Consideró el entorno relacional proyectado desde los Órganos Administrativos Superiores y el Programa de Posgrado en Comunicación de la Facultad de Bibliotecología y el Curso de Pregrado en Comunicación de esta Universidad. Como referencia, hemos observado las iniciativas implementadas y las estructuras organizativas de la Columbia University y la Harvard University. La metodología abarcó las investigaciones bibliográfica, documental y de contenido. La comprensión de las audiencias provino de los enfoques de conceptualización lógica, poder y comunicación. El estudio concluyó que los actores organizacionales influyen en diferentes niveles dentro de las estructuras institucionales, cada uno de acuerdo con sus responsabilidades. Cuanto mayor sea el número de colecciones archivadas, mayor será la red de públicos involucrados, de sus diferentes temas depende el apoyo financiero, de infraestructura, tecnológico, legal y de otro tipo.

Palabras clave: Archivado de la web. Archivamento web. Mapeo de públicos. Relaciones Públicas. Perfil de públicos.

\section{Introdução}

O estudo apresenta conceitos sobre públicos fundamentado na área de Relações Públicas. A partir de pesquisa exploratória descritiva, discorre sobre como esses grupos podem influenciar, de modo positivo ou negativo, nas ações promovidas pelas organizações universitárias observadas.

A sociedade, cada vez mais tecnológica, produz informações com mais velocidade e cria a sensação de esquecimento destas (ROCKEMBACH; PAVÃO, 2018). Essa realidade fez com que diferentes organizações, em nível mundial, se reunissem para implantar iniciativas de preservação da web (CONSÓRCIO INTERNACIONAL DE PRESERVAÇÃO DA INTERNET, 2018).

$\mathrm{O}$ arquivamento da web é um processo que identifica uma informação na World Wide Web (WWW), a captura e a preserva, mantendo seu conteúdo fiel ao original. A captura pode ser extensiva, arquivando maior quantidade de websites, em um nível superficial, como também intensiva, capturando em menor escala, mas em maior profundidade de navegação 
(MASANÈS, 2006). O perfil de conteúdo é classificado conforme a extensão de cada URL ${ }^{1}$, podendo ser agrupado em esferas, como por exemplo, acadêmico-científica, institucional, nacional, por regiões/continentes, por fatos, entre outros.

As iniciativas são desenvolvidas por organizações com diferentes estruturas, cada uma com suas políticas, metas e objetivos (GOMES; MIRANDA; COSTA, 2011). Nesta pesquisa, definimos Organização como uma "entidade social composta de pessoas e de recursos, deliberadamente estruturada e orientada para alcançar um objetivo em comum" (CHIAVENATO, 2003, p. 23). Por sua vez, demanda apoio dos diferentes grupos de influência para atingir sucesso em seus projetos. Esse corpo relacional se configura como públicos - indivíduos, coletivos ou demais organizações que possuem interesses em comum, são afetados e afetam as ações da organização (SIMÕES, 2001). O interesse de cada público é fator determinante no relacionamento, formando um sistema social que influencia as tomadas de decisão (STEFFEN, 2008).

\section{$O$ arquivamento da $w e b$}

O arquivamento da web é o processo que envolve seleção, coleta, armazenamento e recuperação de websites com o objetivo de preservar parte dos conteúdos digitais presentes na $W W W$ (ROCKEMBACH, 2018). Tornou-se a atividade de algumas organizações nãogovernamentais, públicas e de ensino no exterior (FERREIRA; MARTINS; ROCKEMBACH, 2018). As iniciativas buscam a preservação, uma vez que $80 \%$ do conteúdo disseminado via web é alterado após o período de um ano da publicação e 13\% das referências online desaparecem em pouco mais de dois anos (COSTA; GOMES; SILVA, 2017).

Em 2018, 56 organizações integravam o Consórcio Internacional de Preservação da Internet e nove delas eram universidades (CONSÓRCIO INTERNACIONAL DE PRESERVAÇÃO DA INTERNET, 2018). A partir de survey realizado em 2010, Gomes, Miranda e Costa (2011) registraram 42 iniciativas com equipes de número reduzido de pessoas, três dessas eram universitárias. Os escopos de preservação variam entre interesses nacionais, regionais, audiovisuais, institucionais e de literatura. Os projetos estão localizados na América do Norte, Europa, Oceania, Ásia e na América Latina (Chile).

Conforme Brügger (2005), estabelecer estratégias para arquivar a web é fundamental para garantir o sucesso das iniciativas. Nesta perspectiva, a Figura 1 apresenta o Web Archiving Life Cycle Model, exemplo orgânico desenvolvido pela equipe do serviço Archive-it, que demonstra fases do processo estratégico para implantação de arquivos web em diferentes estruturas organizacionais.

1 Uniform Resource Locator - domínios de interesse que devem ser capturados e preservados nos arquivos da web. 
Figura 1 - Web Archiving Life Cycle Model

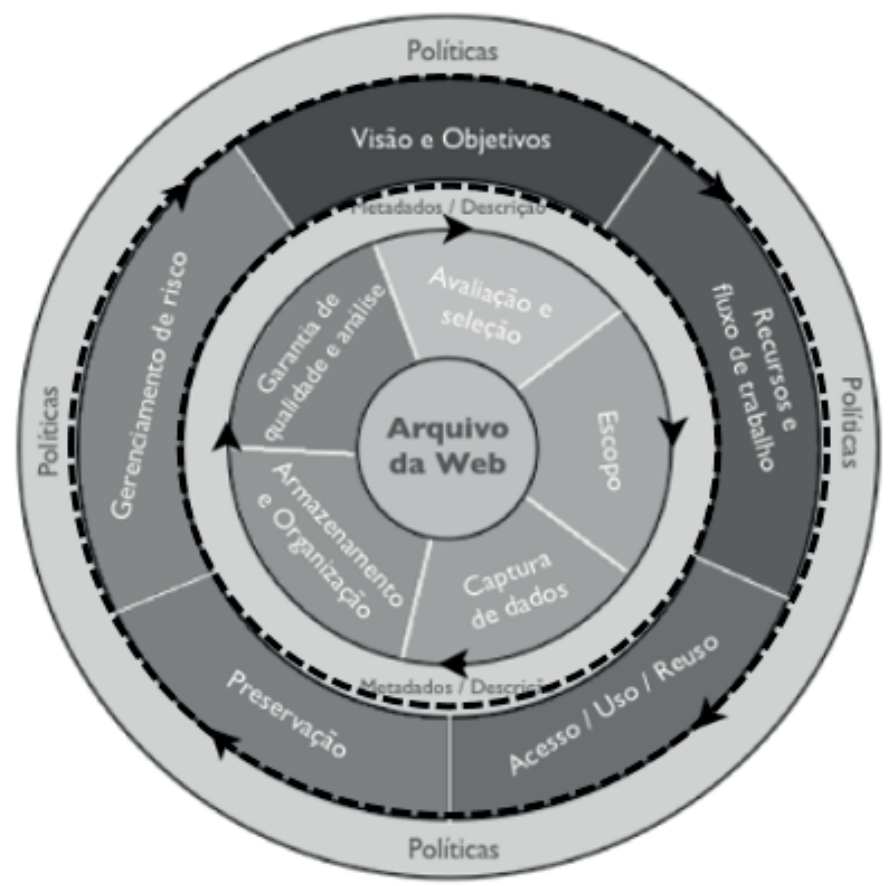

Fonte: Bragg e Hanna (2013 - Tradução nossa).

A faixa mais escura da Figura 1, sinalizada com pontilhados, representa as decisões de alto nível que uma organização se depara ao configurar e gerenciar seu programa de arquivamento na web. Dentre elas: clareza dos objetivos do programa; revisão e planejamento dos recursos disponíveis (fluxo de trabalho, finanças, pessoal, colaboradores e outros) e gerenciamento de riscos, ligado aos direitos autorais dos dados coletados.

\section{Públicos em Relações Públicas}

São variados os conceitos utilizados para públicos em Relações Públicas (RP). Por muito tempo, foram apoiados no critério geográfico/espacial que o objeto - público tomava diante da organização, sendo subdivididos em: interno, misto e externo. Considerada limitada, essa concepção incitou a revisão dos aportes teóricos. Essa relação, agora, é percebida a partir dos critérios de poder e de influência em um sistema social (FRANÇA, 2012, SIMÕES, 1995, STEFFEN, 2008).

Simões (1995) apresentou quatro categorias de públicos, os de decisão, de comportamento, de opinião e de consulta. A primeira identifica os que têm poder de determinar algo sobre a existência da organização e suas iniciativas, juridicamente e legalmente. A segunda denota os que executam as atividades da organização. A terceira espelha os que têm 
poder de influência sobre as ações da organização, mas não, necessariamente, fazem parte de sua estrutura interna. Por último, estão os que interferem de algum modo na tomada de decisão, pois suas opiniões são consideradas importantes no processo.

A partir da perspectiva de comportamento, Hirschman (1970) aponta outros tipos de públicos: os de voz, de saída e de lealdade. Os primeiros são ativos perante as práticas organizacionais, influenciando políticas e resultados. Os de saída caracterizam os que se ausentam do sistema relacional. Os de lealdade buscam contribuir para conquista dos objetivos da organização, sem interferir nas tomadas de decisão.

Steffen (2008) apresenta os enfoques de comunicação e de poder. No primeiro, o relacionamento entre organização e públicos é conduzido pelo discurso e como ele acontece. No segundo, está vinculado à tomada de decisão. Essa visão aponta que o público pode reagir sobre qualquer ação da organização - a favor ou contra ela. A comunicação está vinculada a um processo decisório e demanda o exercício do poder de determinado(s) público(s) (STEFFEN, 2008). Simões (2001) reafirma as categorias de 1995, complementando que os públicos variam conforme complexidade, tamanho e potencial de poder que podem exercer. No mesmo enfoque do poder, a teoria dos stakeholders, de Freeman (2010), considera que o público se revela pelas expressões e pelo exercício de influência, com base nos seus interesses.

O sistema social é sustentado por um processo de comunicação que possui a informação como matéria-prima e é baseado em sete dimensões: a) cultural; b) econômica; c) política: decisão/poder; d) ideológica: ideia-força; e) histórica: tudo ocorre em um espaço e tempo; f) jurídica: caso o conflito não seja solucionado, ele vira uma controvérsia; e g) filosófica: ética; quando cumpre sua responsabilidade e estética, se suas ações e discursos são bem pensados, planejados e executados.

Esse processo se configura em uma linha tênue de cooperação e conflito entre as partes e ocorre de modo não-linear com as seguintes características: a) satisfação: os públicos conscientes, ou não, cooperam ou não colocam obstáculos nas realizações da organização; b) insatisfação: o público não concorda, mas não reage contra; c) boato: o público desinformado dissemina histórias prejudiciais à credibilidade da organização; d) coligações: os públicos, sem informação e atenção, buscam apoio de outros segmentos - ex.: mídia, associações; e) pressão: os públicos se organizam e pressionam a organização para mudar políticas, instigando também a interferência governamental em seu favor; f) conflito: a organização continua com suas políticas sem justificativa aos públicos, gerando conflito e impasse; g) crise: aprofundamento do conflito que pode levar a ruptura do sistema organização-públicos; h) arbitragem: não há entendimento, uma das partes apela para o jurídico, o governo mais uma vez intervém; e i) convulsão social: descontrole da situação, liderança de facções fanáticas (SIMÕES, 2001, STEFFEN, 2008).

Para França (2003, 2009, 2012), a conceituação de públicos ocorre logicamente a partir de três critérios de relacionamento. O primeiro é o grau de dependência jurídica ou situacional da organização perante seus públicos a fim de viabilizar sua constituição, 
existência e permanência no ambiente, mantendo sua produtividade. O segundo é o maior ou menor grau de participação dos públicos nos negócios da organização, na defesa de seus interesses e na sua promoção institucional. O terceiro é o grau de interferência que determinado público pode exercer sobre a organização. São grupos externos, que não as constituem e nem as mantêm, mas podem exercer pressão sobre os seus interesses, objetivos e metas.

A partir da conceituação lógica, é possível formar redes de relacionamento específicas. Os públicos Essenciais (Categoria 1) são ligados juridicamente à organização através de relação prioritária de longo prazo. A dependência é de caráter situacional e varia de acordo com cada organização. Esta Categoria se segmenta em públicos Constitutivos - os quais fornecem recursos para a constituição da organização e a empreendem, e públicos Não-constitutivos ou de Sustentação - os quais viabilizam a existência da organização, mantendo a produtividade e colaborando para as atividades-fim. Esses últimos se dividem em Primários (colaboradores diretos e usuários/clientes que viabilizam iniciativa em maior grau de dependência) e Secundários (em menor grau de dependência).

$\mathrm{Na}$ Categoria 2, encontram-se os públicos Não-essenciais: que possuem maior ou menor grau de participação na organização. Executam atividades-meio, prestando serviços externos. Na Categoria 3, os públicos de Redes de Interferência: entidades congêneres que atuam com os mesmos objetivos e características; veículos de comunicação de massa (impressa, eletrônica e digital) que podem interferir na opinião pública e possuem alto risco relacional e grupos de ativistas e ideológicas, estruturadas nacional e internacionalmente, atingem a opinião pública em defesa de diferentes causas.

\section{Configurações estruturais organizacionais de universidades federais no Brasil}

A forma de organização de uma instituição influencia em seus resultados, se mal estruturada pode gerar atritos, aprofundar disputas desimportantes e salientar deficiências de gestão (DRUCKER, 1977). É a estrutura organizacional que define a interligação dos grupos especializados e pode ser definida como resultado do processo de distribuição da autoridade exercida por seus atores (públicos). O sistema de comunicação perpassa toda a estrutura da organização; é por meio dele que o poder é exercido para a tomada de decisão (MAXIMIANO, 1985, VASCONCELLOS; HEMSLEY, 1986).

Machado (1998) dá ênfase aos modelos estratégicos para estruturas organizacionais de universidades; entre eles, está o modelo tradicional do tipo comissão e colegiado, o qual adota uma administração plural para tomada de decisão. Essas comissões e colegiados são formados por membros internos da organização, provenientes de diferentes segmentos, departamentos e profissões (CURY, 1988). No caso de universidades federais de ensino superior, esse tipo de estrutura é concretizado por meio dos conselhos universitários, de curadores e de ensino, 
pesquisa e extensão (UNIVERSIDADE FEDERAL DO RIO GRANDE DO SUL, 19951996). A complexa estrutura organizacional do modelo tradicional exercida por meio de comissão e colegiado retrata a administração plural, porém demanda articulação entre os diversos atores.

\section{Metodologia}

A pesquisa exploratório-descritiva ocorreu em três etapas. Primeiramente, levantamento bibliográfico (STUMPF, 2008) para conhecer o contexto do arquivamento da web. A busca ocorreu na Scopus, Web of Science, Google Scholar e SciELO Citation Index por artigos publicados entre 2010 e 2017 - associando os temas: arquivamento da web, públicos e estruturas organizacionais.

A segunda consistiu na coleta de dados sobre as universidades e suas plataformas de arquivamento da web. As fontes - estatutos, regimentos, organogramas, comunicações e mensagens de websites - escolhidas a partir da regra de pertinência, corresponderam aos objetivos do estudo, período e procedimentos de análise (BARDIN, 2004, FONSECA JÚNIOR, 2008). As categorias de dados sobre as organizações universitárias foram: classificação, missão, visão, governança e estrutura. Nas plataformas de arquivamento da web: coleções, descrição, direitos autorais, tempo de arquivamento, assuntos, quem coleta os conteúdos, categoria do URL.

A partir da categorização, elaboraram-se quadros identificando os públicos e suas respectivas funções na estrutura organizacional. Isso permitiu aferir a influência destes atores nos diferentes níveis para, então, formar os gráficos hierárquicos. Os públicos foram reconhecidos a partir da “Identificação e Mapeamento dos Públicos” (IMP) de França (2012), e as visões de Simões (2001) e Steffen (2008). Para isso listaram-se os públicos que se relacionavam com as iniciativas e os que faziam parte da estrutura organizacional conforme as regras de governança; determinaram-se os tipos de relacionamento estabelecidos; definiu-se o objetivo destes relacionamentos, a partir de suas responsabilidades na estrutura; indicou-se o nível de envolvimento, a partir dos graus de dependência, participação e interferência; e, assim, categorizaram-se os públicos entre: essenciais, não-essenciais e redes de interferência.

Os quadros também englobaram os indicadores: tipo de relacionamento: administrativo, classista, institucional, legal, negócios, operacional, parceria total, política, profissional, social; nível de envolvimento: frequente, permanente, ocasional e sazonal; critérios de relacionamento: I. grau de dependência jurídica ou situacional; II. maior ou menor grau de participação dos públicos nas ações e III. grau de interferência que determinado público pode exercer sobre a organização e seus negócios.

A terceira etapa dissertou sobre a estrutura da UFRGS, utilizando como subsídio o “Estatuto e o Regimento Geral da Universidade (1995-1996)”, além dos conteúdos disponíveis 
no website, com suas respectivas extensões do domínio “ufrgs.br”. A partir da identificação da governança e da estrutura, ocorreu o delineamento dos públicos de acordo com os passos citados na IMP.

Com as informações de cada objeto, elaboraram-se recortes contemplando as categorias escolhidas. A influência dos atores, nos diferentes níveis, foi observada com base na descrição de suas funções e atribuições dentro da estrutura organizacional da Universidade, a partir da análise documental e de conteúdo realizada (BARDIN, 2004, MOREIRA, 2008).

\section{Resultados}

Esta seção apresenta as redes de públicos mapeados de modo hierárquico

\section{A iniciativa de arquivamento da web da Universidade de Harvard}

A iniciativa é viabilizada por meio da tecnologia disponibilizada pelo Archive-it, serviço de arquivamento da web oferecido pela organização Internet Archive. Este possibilita que a Universidade autogerencie suas coleções, coletando, criando e preservando conteúdos digitais de interesse de seus públicos (ARCHIVE-IT.ORG, 2014).

No período da pesquisa, nove organizações coletoras faziam parte da iniciativa, com 69 coleções, formadas pela captura de 17.083 URL internos e externos ao ambiente digital da Universidade. Dentre essas, 42 coleções pertenciam à organização coletora Harvard Business School (HBS) e preservavam um histórico dos negócios de empresas, indústrias, indivíduos, movimentos locais e da história institucional da HBS. Os principais componentes das capturas incluíam arquivos de ensino e documentos de pesquisa do corpo docente, bem como os registros oficiais de todos os departamentos administrativos. Entre os conteúdos: textos, imagens e outros formatos multimídia, páginas da web interligadas, boletins informativos e blogs. As estratégias e as políticas de coleta das nove organizações convergiam para o mesmo fim, pesquisa, ensino e preservação da história institucional da Universidade.

Esta iniciativa é amparada por uma rede formada por 23 perfis de públicos e seus respectivos subgrupos, representados na Figura 2. 
Figura 2-Gráfico hierárquico dos públicos da iniciativa da Universidade de Harvard

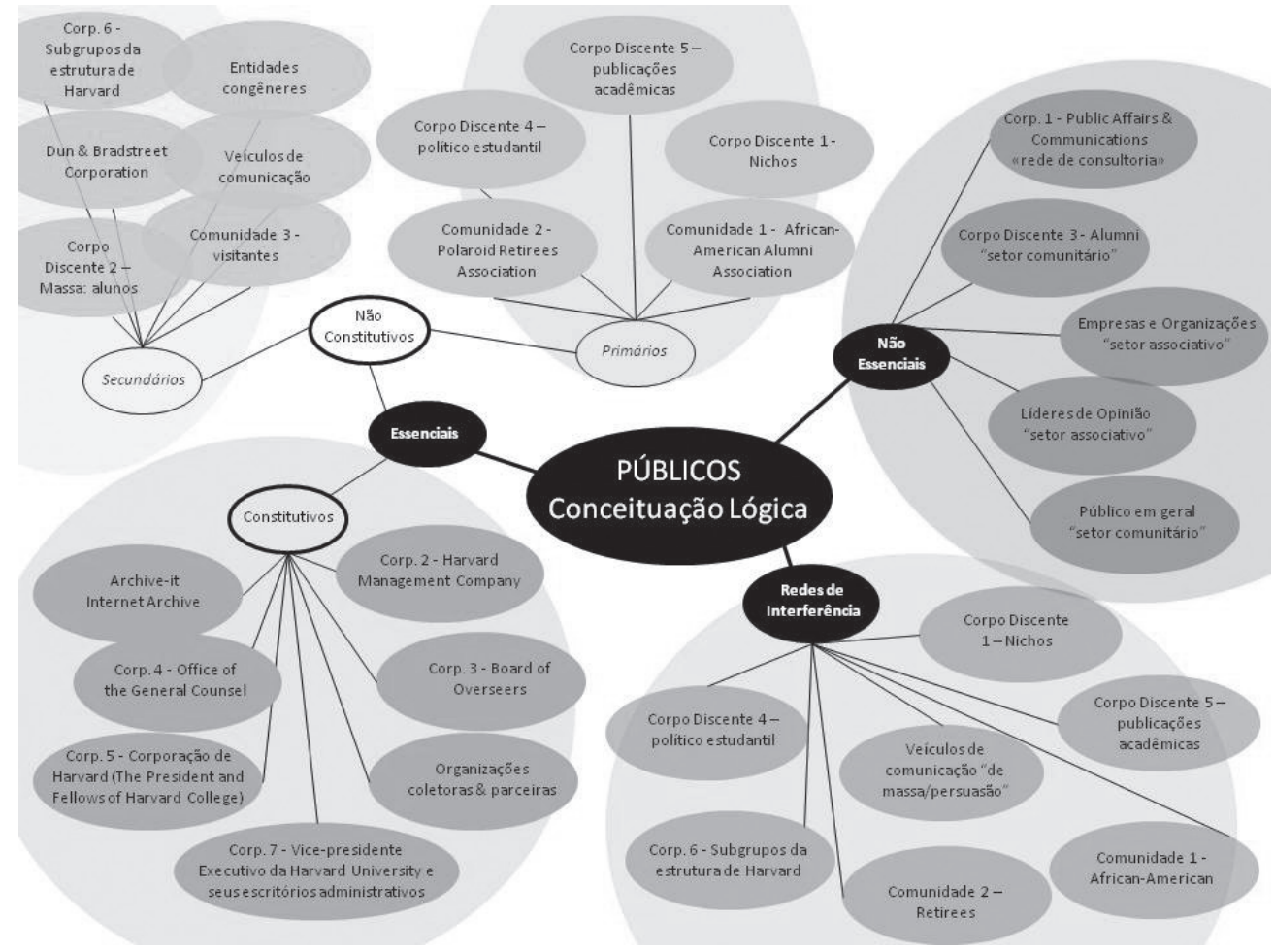

Fonte: dados da pesquisa, elaborado pelos autores.

Os públicos mapeados fazem parte não apenas da iniciativa, como também da governança e da estrutura da Universidade. A administração dessa organização universitária se dá por meio de duas diretorias principais. A primeira é a Corporação de Harvard, formada pelo presidente e os membros do Harvard College (Fellows), e a segunda, pelo Conselho de Superintendentes ou Supervisores (Board of Overseers). Todavia, a pesquisa documental identificou, também, outros departamentos e escritórios que fazem parte da estrutura organizacional, os quais podem influenciar na tomada de decisão devido às responsabilidades administrativas, jurídicas e financeiras que possuem na Universidade.

\section{A iniciativa de arquivamento da web da Universidade de Columbia}

Também viabilizada por meio da tecnologia do Archive-it, está iniciativa conta com alguns públicos para criar suas coleções de arquivos web. Entre eles: funcionários, pesquisadores, ex-alunos e organizações estudantis.

Três organizações coletoras são responsáveis por 12 coleções, formadas pela captura de 2.841 URL internos e externos ao ambiente digital da Universidade. As coleções preservam textos, imagens, páginas da web interligadas, grupos de notícias, boletins informativos, 
publicações estudantis e blogs. Grande parte se caracteriza pelo perfil institucional, porém alguns escopos abrangem conteúdo internacional.

A governança geral da Universidade está nas mãos do Senado Universitário e ocorre democraticamente. Os curadores (Trustees) supervisionam os cargos administrativos, monitoram o orçamento e protegem a propriedade. Esse Senado é formado por representantes de diferentes setores, incluindo administrativo, faculdades, estudantes, instituições filiadas, equipe da biblioteca profissional, pesquisa e alumnis. Como a Universidade de Harvard, a Columbia também é subdividida em vários campi, possuindo o total de 16 unidades, entre faculdades e escolas (COLUMBIA UNIVERSITY, 1959).

A pesquisa identificou também outros departamentos e escritórios ligados à Columbia University Libraries, os quais podem influenciar na tomada de decisão referente à iniciativa, uma vez que é a biblioteca a promotora do projeto. À vista disso, a Figura 3 demonstra a rede com 10 perfis de públicos.

Figura 3 - Gráfico hierárquico públicos da iniciativa da Universidade de Columbia

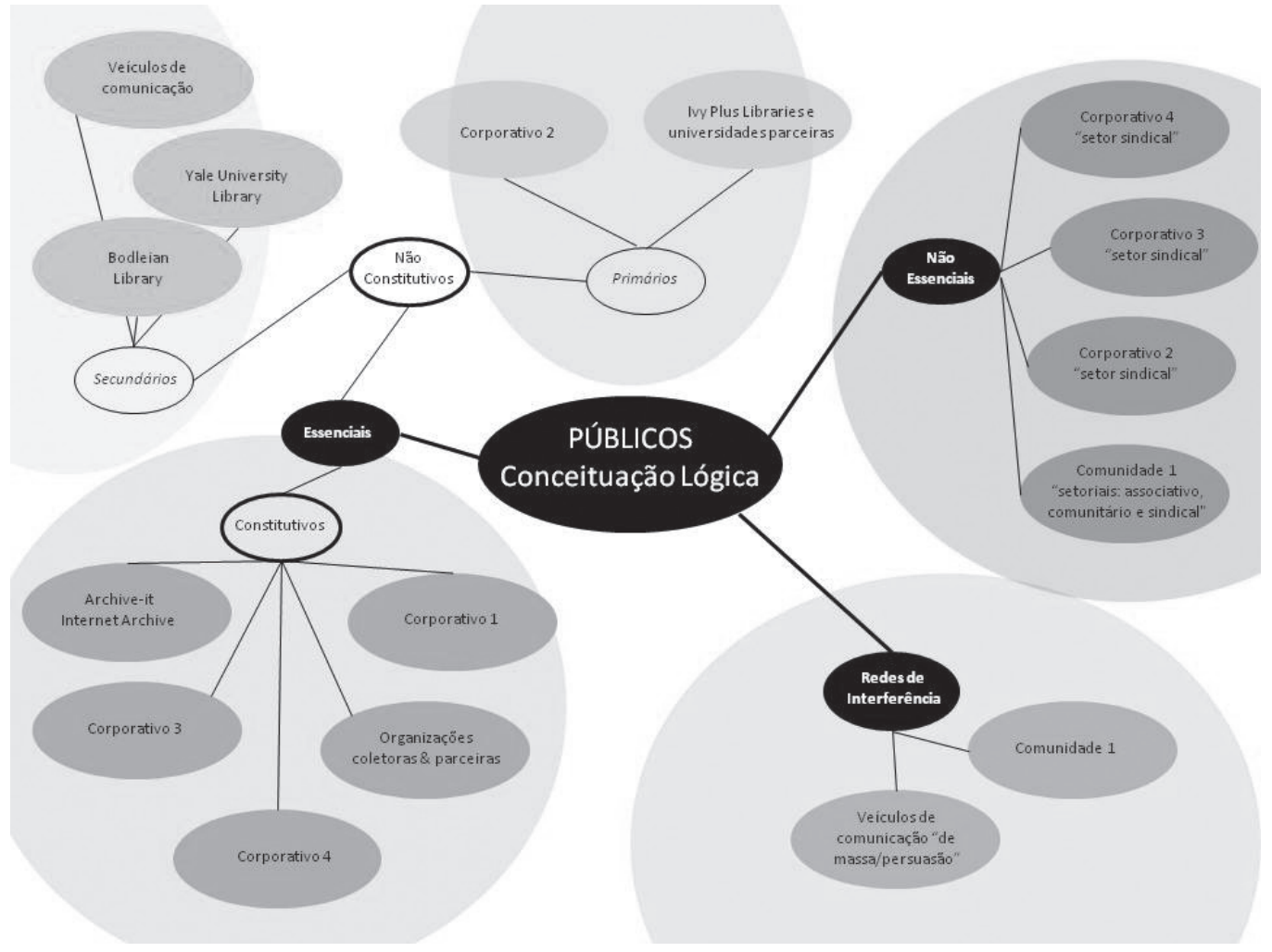

Fonte: dados da pesquisa, elaborado pelos autores.

Os públicos, mesmo estando em uma categoria, podem ser integrados por subcomponentes de outra. Por exemplo, um público essencial não-constitutivo primário pode 
se vincular a um essencial constitutivo em detrimento de uma tomada de decisão ou política relacionada à coleta de dados. Como também, o mesmo público se encaixar em classificação diferente, devido a sua característica particular de tipo de relacionamento.

\section{A estrutura organizacional e a potencial rede de públicos da UFRGS}

Com sede em Porto Alegre, a Universidade Federal do Rio Grande do Sul (UFRGS) oferece cursos em diferentes áreas, desde o ensino fundamental até a pós-graduação. Na sua estrutura são registrados mais de 700 grupos de pesquisa formados por alunos de graduação e pós-graduação, técnicos de laboratório, docentes e visitantes, com um corpo de, aproximadamente, 14 mil pessoas (UNIVERSIDADE FEDERAL DO RIO GRANDE DO SUL, Pesquisa e Inovação 2018).

Para atingir seus objetivos, a Universidade se estrutura em órgãos da administração superior; 29 unidades universitárias²; entre outros ${ }^{3}$. São órgãos da administração superior, o Conselho de Curadores (CONCUR); o Conselho Universitário (CONSUN); o Conselho de Ensino, Pesquisa e Extensão (CEPE) e a Reitoria. Esses conselhos são geridos democraticamente e compostos por diferentes representações - docentes, discentes, ex-alunos, servidores, representantes de entidades de trabalhadores, culturais, como também do setor de ciência e tecnologia, além de membros externos, indicados pelo Ministério da Educação, por exemplo. Os dois primeiros conselhos são os órgãos máximos da UFRGS, possuindo poder sobre várias instâncias e decisões na estrutura organizacional.

Cada uma das unidades universitárias, como também boa parte dos grupos de pesquisa, possui seus websites próprios. Os conteúdos são gerenciados pelas equipes de cada um, conforme os interesses de seus públicos (UNIVERSIDADE FEDERAL DO RIO GRANDE DO SUL, Unidades Regionais e Acadêmicas, 2018). A Figura 4 representa a rede composta por 16 públicos estratégicos ligados à Administração Superior da UFRGS.

Institutos centrais, faculdades ou escolas, com seus órgãos auxiliares.

Hospital universitário; institutos especializados e centros de estudos interdisciplinares. 
Figura 4 - Gráfico hierárquico órgãos da administração superior da UFRGS

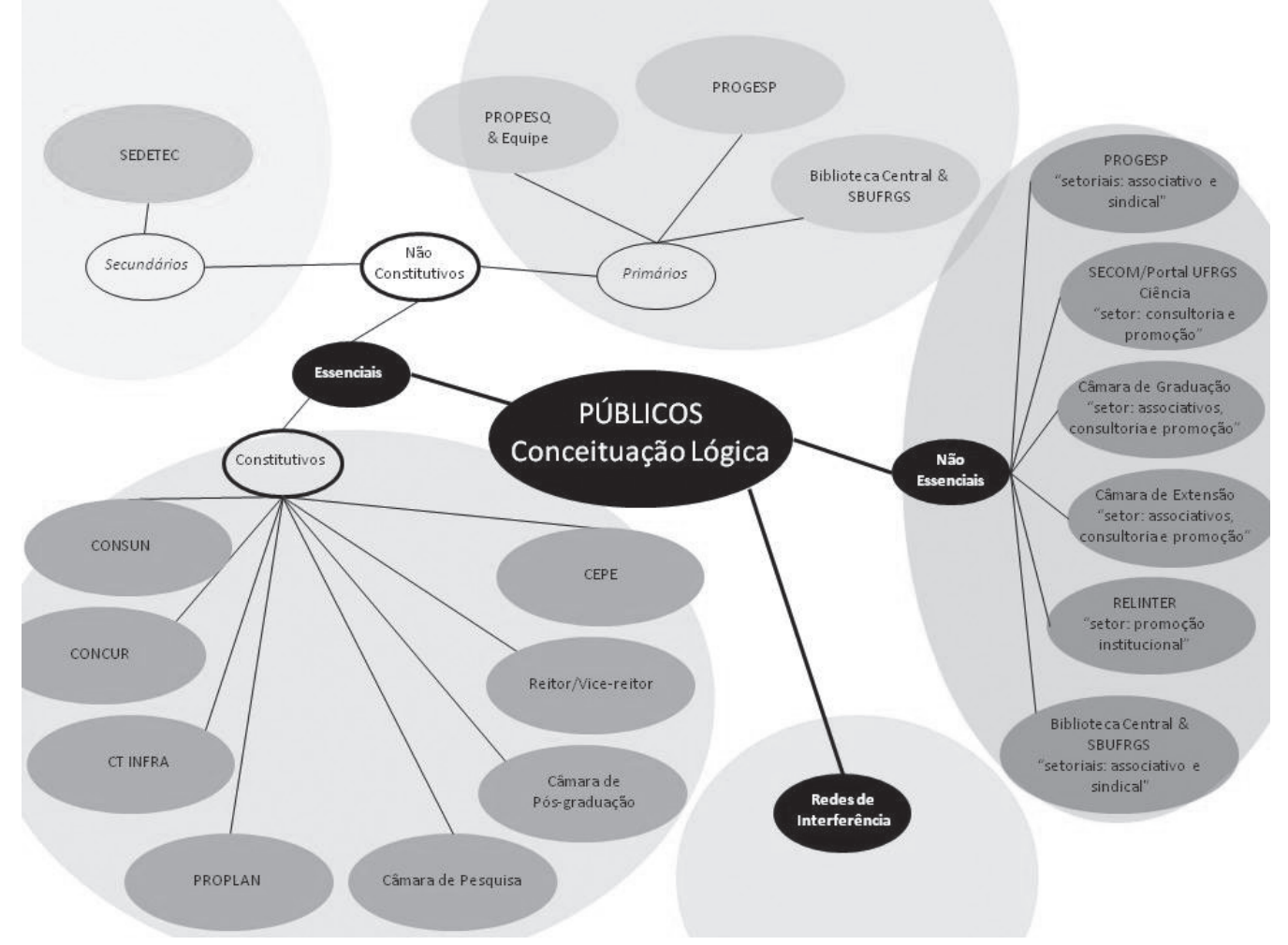

Fonte: dados da pesquisa, elaborado pelos autores.

Um mesmo público pode se encaixar em classificação diferente, devido a sua característica particular de tipo de relacionamento. A imagem aponta as possíveis influências dos públicos, que podem agir como parceiros ou não da iniciativa. Esses grupos são variados conforme complexidade, tamanho e potencial de poder que podem exercer nos quesitos de consulta, de decisão, de comportamento e de opinião.

Vinculadas à Reitoria, estão diferentes pró-reitorias, como a PROGESP 4 , a PROPLAN ${ }^{5}$ e a SEDETEC 6 . Estas podem influenciar de modos diferentes para a implantação de um projeto de arquivamento da web na UFRGS, uma vez que, a partir de suas ações e responsabilidades é possível: a) conseguir apoio técnico-administrativo para operação e concretização da iniciativa, caso seja necessário alocação de servidores para execução e manutenção das atividades de arquivamento da web; b) buscar assistência desse público para as atividades da iniciativa no que tange a orçamentos, celebração e acompanhamento de contratos e convênios, aquisições de bens e serviços, importação de equipamentos e serviços para o suporte à pesquisa e c) promover a

4 Pró-Reitoria de Gestão de Pessoas.

5 Pró-Reitoria de Planejamento.

6 Secretaria de Desenvolvimento Tecnológico. 
iniciativa para que haja parceria e colaboração, a fim de propiciar desenvolvimento tecnológico para a realização do arquivamento.

Na perspectiva das unidades universitárias, apresenta-se a Faculdade de Biblioteconomia e Comunicação (FABICO), a qual oferece seis cursos de graduação e três programas de pós-graduação ${ }^{7}$ - um em Comunicação (PPGCOM), um em Museologia e Patrimônio (PPGMUSPA) e um em Ciência da Informação (PPGCIN). A faculdade possui URL próprio com extensões específicas para cada curso de graduação. Já os PPGs possuem, além das extensões, seus endereços particulares para comunicação de informações (matrículas; disciplinas; quadro de docentes; publicações; linhas, projetos e grupos de pesquisa; documentos; formulários; entre outros) com seus públicos (UNIVERSIDADE FEDERAL DO RIO GRANDE DO SUL, FABICO, 2018).

Cada um dos cursos stricto sensu possui um conselho, coordenado por uma comissão de pós-graduação gerida democraticamente por docentes e discentes, conforme os artigos $49^{\circ}$ e $50^{\circ}$ do Estatuto e Regimento Geral (UNIVERSIDADE FEDERAL DO RIO GRANDE DO SUL, 1995-1996). Somente o PPGCOM possui 15 grupos de pesquisa devidamente registrados no Conselho Nacional de Desenvolvimento Científico e Tecnológico (CNPq). A Figura 5 representa a segunda rede de relacionamento elaborada a partir da observação da estrutura organizacional de uma das unidades da UFRGS.

7 Stricto Sensu. 
Figura 5 - Gráfico hierárquico FABICO - UFRGS

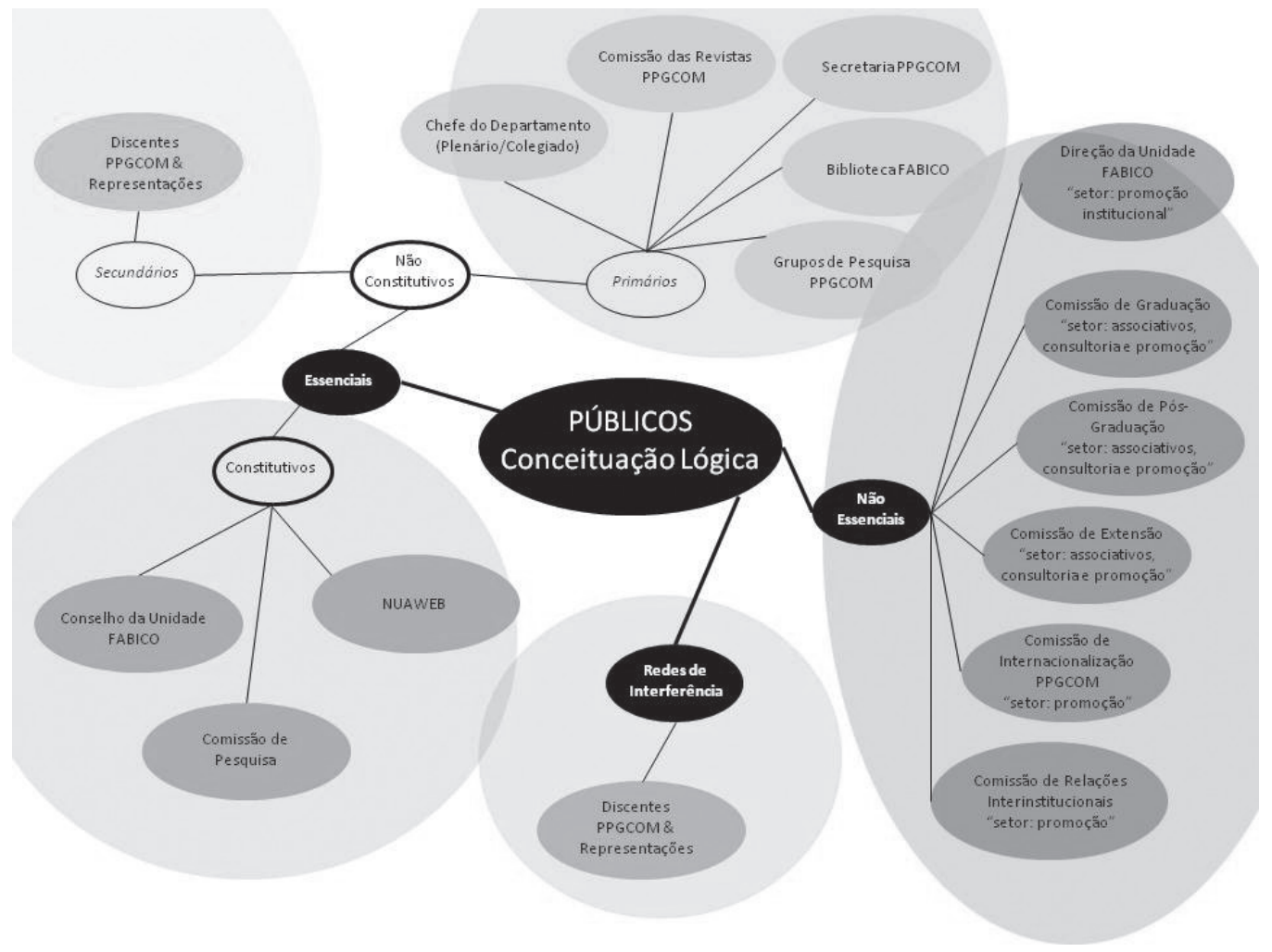

Fonte: Dados da pesquisa, elaborado pelos autores.

A figura apresenta o mapeamento dos 15 públicos da potencial rede formada na FABICO (PPGCOM). Eles exercem diferentes níveis de influência conforme suas funções como, por exemplo, a criação, extinção ou reestruturação de departamentos; aprovação dos planos de ação, elaboração da proposta orçamentária; como também funde e cria comissões, assessorias ou mecanismos necessários ao cumprimento das atribuições da unidade. A partir do desmembramento de cada esfera do gráfico, podemos chegar a uma amplitude relacional maior, mesmo em uma perspectiva micro-organizacional.

\section{Considerações finais}

São diversos os perfis das organizações que promovem o arquivamento da web internacionalmente. As iniciativas apresentam diferentes escopos de coleta, conforme políticas e estratégias estabelecidas pelas organizacões.

As instituições de ensino são compostas física e organizacionalmente por vários campi universitários. Suas estruturas são interligadas por grupos especializados e podem ser definidas como resultado do processo de distribuição da autoridade exercida por seus 
atores (públicos). Entende-se que o sistema comunicacional perpassa as estruturas, já que a administração das universidades ocorre de modo plural através de comissões, colegiado e conselhos, fazendo com que o poder seja exercido nos diversos níveis e em diferentes graus.

As iniciativas de arquivamento da web implantadas no exterior apresentam coleções que constituem uma espécie de memória web de suas entidades, com escopos de conteúdos organizacionais, institucionais, de fatos e eventos específicos. Essas coleções são concebidas por várias organizações coletoras, que não apenas as entidades macropromotoras das iniciativas e alguns públicos agem diretamente na formação delas. Algumas das organizações coletoras são partes das estruturas organizacionais das universidades e, independente da sua ligação, por vezes, monitoram e capturam URL além dos domínios “columbia.edu” e "harvard.edu”.

Percebe-se que os públicos podem facilitar as tomadas de decisão, principalmente no que tange às deliberações de alto nível do Web Archiving Life Cycle Model. Quanto maior a quantidade de coleções arquivadas, maior a rede de públicos envolvidos. No caso da UFRGS, pode-se dizer que a rede de relacionamento também se configura de forma complexa. Isso se deve a característica de governança, estrutura de multi campi e aos subgrupos que exercem voz na tomada de decisão. Para finalizar, os públicos são agentes fundamentais no processo para aperfeiçoar resultados das iniciativas e otimizar custos de investimento, uma vez que influenciam nas ações das organizações, estabelecendo os mais variados tipos de relacionamento, comunicação e poder.

\section{Referências}

ARCHIVE-IT.ORG. Website [on-line], 2014. Disponível em: https://archive-it.org/. Acesso em: 23 out. 2018. BARDIN, L. Análise de conteúdo. 3ª ed. Lisboa: Edições 70, 2004.

BRAGG, M.; HANNA, K. The Web Archiving Life Cycle Model, March 2013. Disponível em: http://ait.blog. archive.org/files/2014/04/archiveit_life_cycle_model.pdf. Acesso em: 16 abr. 2019.

BRÜGGER, N. Archiving Websites: General Considerations and Strategies. Århus: The Centre for Internet Research, 2005.

CHIAVENATO, I. Introdução à teoria geral da administração. $7^{\text {a }}$ ed. Rio de Janeiro: Elsevier, 2003.

COLUMBIA UNIVERSITY, in the City of New York. Charters and Statutes. Edition of April 6, 1959. Disponível em: https://secretary.columbia.edu/files/secretary/university_charters_ and_ statutes/ UniversityStatues_December2017.pdf. Acesso em: 25 out. 2018.

CONSÓRCIO INTERNACIONAL DE PRESERVAÇÃO DA INTERNET. Website [on-line]. Disponível em: http://netpreserve.org. Acesso em: 24 abr. 2018.

COSTA, M.; GOMES, D.; SILVA, M. J. The evolution of web archiving. International Journal on Digital Libraries, 1-15. DOI: 10.1007\%2Fs00799-016-0171-9, 2017.

CURY, A. Organização e métodos: perspectiva comportamental e abordagem contingencial. 4. ed. São Paulo: Atlas, 1988.

DRUCKER, P. Introdução à administração. São Paulo: Pioneira, 1977. 
FERREIRA, L.; MARTINS, M. R.; ROCKEMBACH, M. Usos do arquivamento da web na comunicação científica, 2018. DOI 10.21747/16463153. Disponível em: http://ojs.letras.up.pt/index.php/prismacom/article/ view/3927. Acesso em: 28 maio 2018.

FONSECA JÚNIOR, W. C. Análise de conteúdo. In: DUARTE, J.; BARROS, A. (Orgs.) Métodos e técnicas de pesquisa em comunicação. 2a . ed. São Paulo: Atlas, 2008. p. 280-303.

FRANÇA, F. Públicos, como identificá-los em nova visão estratégica: business relationship. $3^{\mathrm{a}}$. ed. São Caetano do Sul, SP: Yendis, 2012.

FRANÇA, F. Como construir relacionamentos corporativos eficazes. In: FRANÇA, F.; GRUNIG, J. E. (Orgs.). Relações Públicas: teoria, contexto e relacionamentos. São Caetano do Sul, SP: Difusão, 2009.

FRANÇA, F. Conceituação lógica de públicos em relações públicas. Estudos de Jornalismo \& Relações Públicas. São Bernardo do Campo, SP, v.1, n.1, jun. 2003. p. 17-31.

FREEMAN, E. et al. Stakeholder Theory: The State of the Art. Cambridge University Press. The Edinburgh Building, Cambridge CB2 8RU, UK, 2010.

GOMES, D; MIRANDA, J.; COSTA, M. A survey on web archiving initiatives. In: INTERNATIONAL CONFERENCE ON THEORY AND PRACTICE OF DIGITAL LIBRARIES. Lisboa, POR: Springer Berlin Heidelberg, 2011. p. 408-420. Disponível em: https://link.springer.com/ content/ pdf/10.1007\%2F978-3-642-24469-8_41.pdf. Acesso em: 6 out. 2017.

INTERNET ARCHIVE. Website. Disponível em: https://archive.org/. Acesso em: 24 abr. 2018.

MACHADO, N. S. Configurações estruturais em organizações universitárias: o caso a Universidade do Oeste de Santa Catarina. 1998. 236 f. Dissertação (Mestrado em Administração), Curso de Pós-Graduação em Administração, Universidade Federal de Santa Catarina.

MASANÈS, J. Web Archiving. Paris, FRA: Springer-Verlag Berlin Heidelberg, 2006.

MAXIMIANO, A. C. A. Introdução à administração. 2a. ed. São Paulo: Atlas, 1985.

MOREIRA, S. Análise documental como método e como técnica. In: DUARTE, J.; BARROS, A. (Orgs.) Métodos e técnicas de pesquisa em comunicação. 2a . ed. São Paulo: Atlas, 2008. p. 269-279.

ROCKEMBACH, M. Arquivamento da web: Estudos de caso internacionais e o caso Brasileiro. Revista Digital Biblioteconomia e Ciência da Informação, v. 16, n. 1, jan./abr. 2018. Disponível em: https:// periodicos.sbu.unicamp.br/ojs/ index.php/rdbci/article /view/ 8648747/pdf. Acesso em: 18 ago. 2018.

ROCKEMBACH, M.; PAVÃO, C. M. G. Políticas e tecnologias de preservação digital no arquivamento da Web. v. 11, n. 1, 2018. DOI: https://doi.org/10.26512/ rici.v11.n1. 2018.8473. Disponível em: http:// periodicos.unb.br/ ojs311/index.php/RICI/ article/view/8473. Acesso em: 18 out. 2018.

SIMÕES, R. P. Relações públicas e micropolítica. São Paulo: Summus, 2001.

SIMÕES, R. P. Relações públicas: função política. São Paulo: Summus, 1995.

STEFFEN, A. M. O conceito de público em relações públicas. Porto Alegre: Cidadela, 2008.

STUMPF, I. R. C. Pesquisa bibliográfica. In: DUARTE, J.; BARROS, A. (Orgs.) Métodos e técnicas de pesquisa em comunicação. $2^{a}$. ed. São Paulo: Atlas, 2008. p. 51-61.

UNIVERSIDADE FEDERAL DO RIO GRANDE DO SUL. Estatuto e regimento geral da Universidade Federal do Rio Grande do Sul. 1995-1996. Disponível em: https://www.ufrgs.br/institutodeartes/wpcontent/uploads/2018/03/Estatuto-e-Regimento-Geral-da-UFRGS.pdf. Acesso em: 17 set. 2018.

UNIVERSIDADE FEDERAL DO RIO GRANDE DO SUL. Website [on-line]. Disponível em: http://www. ufrgs.br/ufrgs/inicial. Acesso em: 19 nov. 2018. 
UNIVERSIDADE FEDERAL DO RIO GRANDE DO SUL. a-ufrgs. Organograma, [on-line]. Disponível em: http://www.ufrgs.br/ufrgs/a-ufrgs/organograma. Acesso em: 19 nov. 2018.

UNIVERSIDADE FEDERAL DO RIO GRANDE DO SUL. Biblioteca Central, [on-line]. Disponível em: https://www.ufrgs.br/bibliotecacentral/. Acesso em: 23 nov. 2018.

UNIVERSIDADE FEDERAL DO RIO GRANDE DO SUL. Ensino, [on-line]. Disponível em: http://www. ufrgs.br/ufrgs/ensino. Acesso em: 23 nov. 2018.

UNIVERSIDADE FEDERAL DO RIO GRANDE DO SUL. FABICO, [on-line]. Disponível em: http://www. ufrgs.br/fabico. Acesso em: 22 nov. 2018.

UNIVERSIDADE FEDERAL DO RIO GRANDE DO SUL. Grupos de Pesquisa, [on-line]. Disponível em: http://www.ufrgs.br/ppgcom/ pesquisa/grupos_de_pesquisa. Acesso em: 19 nov. 2018.

UNIVERSIDADE FEDERAL DO RIO GRANDE DO SUL. Pesquisa e Inovação, [on-line]. Disponível em: http://www.ufrgs.br/ufrgs/pesquisa-e-inovacao/apresentacao . Acesso em: 19 nov. 2018.

UnIVERSIDAde federal DO RIO GRANDE DO SUl. Portal da Pesquisa, [on-line]. Disponível em: http://www.ufrgs.br/portaldapesquisa/. Acesso em: 23 nov. 2018.

UNIVERSIDADE FEDERAL DO RIO GRANDE DO SUL. PROGESP, [on-line]. Disponível em: http:// www.ufrgs.br/progesp/progesp-1. Acesso em: 20 nov. 2018.

UNIVERSIDADE FEDERAL DO RIO GRANDE DO SUL. PROPESQ. CT-INFRA, [on-line]. Disponível em: http://www.ufrgs.br/propesq1/ctinfra/. Acesso em: 20 nov. 2018.

UNIVERSIDADE FEDERAL DO RIO GRANDE DO SUL. PROPLAN, [on-line]. Disponível em: https:// www.ufrgs.br/proplan/quem-somos/apresentacao/. Acesso em: 21 nov. 2018.

UNIVERSIDADE FEDERAL DO RIO GRANDE DO SUL. RELINTER, [on-line]. Disponível em: http:// www.ufrgs.br/relinter/portugues/menurelinter/a-relinter. Acesso em: 22 nov. 2018.

UNIVERSIDADE FEDERAL DO RIO GRANDE DO SUL. SECOM, [on-line]. Disponível em: http://www. ufrgs.br/secom/. Acesso em: 21 nov. 2018.

UNIVERSIDADE FEDERAL DO RIO GRANDE DO SUL. SEDETEC, [on-line]. Disponível em: https:// www.ufrgs.br/sedetec/. Acesso em: 22 nov. 2018.

UNIVERSIDADE FEDERAL DO RIO GRANDE DO SUL. Unidades Regionais e Acadêmicas, [on-line]. Disponível em: http://www.ufrgs.br/ufrgs/a-ufrgs/unidades-academicas. Acesso em: 22 nov. 2018.

VASCONCELLOS, E.; HEMSLEY, J. R. Estrutura das organizações: estruturas tradicionais, estruturas para inovação, estrutura matricial. São Paulo: Pioneira, 1986.

\section{Marina Rodrigues Martins}

Doutoranda em Comunicação e Mestra em Comunicação e Informação pelo Programa de Pósgraduação em Comunicação da Universidade Federal do Rio Grande do Sul (PPGCOM/UFRGS) - Linha 1: Informação, Redes Sociais e Tecnologias. Tutora do Curso de Graduação em Relações Públicas na UNISINOS - modalidade EAD. Pós-graduada em Marketing Digital, pela ESPM-Sul e Bacharel em Comunicação Social - habilitação em Relações Públicas, pela UNISINOS. E-mail: mrodriguesmartins@gmail.com. 


\section{Moisés Rockembach}

Professor Doutor do Programa de Pós-Graduação em Comunicação (PPGCOM/UFRGS) e Programa de Pós-Graduação em Ciência da Informação (PPGCIN/UFRGS). Pós-Doutorado em Ciência da Informação (Universidade do Porto). Doutor em Informação e Comunicação em Plataformas Digitais (Universidade do Porto e Universidade de Aveiro). Líder do Núcleo de Pesquisa em Arquivamento da Web e Preservação Digital (NUAWEB/UFRGS). Possui diversos artigos publicados em periódicos nacionais e internacionais, como as revistas Information Research e a International Review of Information Ethics, tratando de arquivamento da web, preservação digital, avaliação da informação e ética da informação em ambientes digitais. E-mail: moises.rockembach@ufrgs.br.

Recebido em: 15.03.2019

Aprovado em: 09.09.2019

Este artigo é publicado em acesso aberto (Open Access) sob a licença Creative Commons Attribution Non-Commercial (CC-BY-NC), que permite uso, distribuição e reprodução em qualquer meio, sem restrições, desde que sem fins comerciais e que o trabalho original seja corretamente citado. 